PROVETAS E CLONES: UMA ANTROPOLOGIA DAS NOVAS TECNOLOGIAS REPRODUTIVAS. Luna N. Rio de Janeiro: Editora Fiocruz; 2007. 300 p. (Coleção Antropologia e Saúde). ISBN: 85-7541-136-0

\section{Etnografia da infertilidade}

Uma geração de pesquisadores sociais assumiu o tema da infertilidade e das novas tecnologias reprodutivas como desafio de pesquisa no Brasil 1,2,3,4,5,6,7. Como nenhuma outra tecnologia reprodutiva, as técnicas conceptivas provocam valores fundamentais de nosso ordenamento social ao medicalizar o desejo por filhos. O livro Provetas e Clones: Uma Antropologia das Novas Tecnologias Reprodutivas, fruto da tese de Doutorado de Naara Luna, é a publicação mais recente na interface da Antropologia e da Saúde Pública. A questão de pesquisa de Luna foi eminentemente antropológica - o impacto das tecnologias reprodutivas nas concepções de parentesco e pessoa - mas seus dados de campo extrapolam a Antropologia e tocam em questões fundamentais à Saúde Pública, como o direito à saúde, o estatuto do embrião e a medicalização da reprodução.

Uma das principais novidades da obra é a riqueza etnográfica da pesquisa realizada em três centros públicos brasileiros. São poucos os hospitais públicos com oferta de serviços de tecnologias reprodutivas no país, e Luna coletou seus dados nos principais centros brasileiros. O início da obra descreve os desafios da negociação para a entrada no campo, um tema recorrente às etnografias brasileiras e internacionais na interface do segredo e das questões reprodutivas. No entanto, Luna enfrentou um desafio adicional: seu projeto de pesquisa, uma etnografia da infertilidade, foi entendido como relativo à área temática especial, ou seja, exigiu-se que a pesquisadora não apenas submetesse seu projeto aos comitês de ética em pesquisa de cada hospital, mas também que fosse avaliado pela Comissão Nacional de Ética em Pesquisa (CONEP). Esse é um dado da pesquisa que não deve ser menosprezado, pois aponta para dois fenômenos do sistema brasileiro de revisão ética: (i) a pouca compreensão da regulamentação em vigor, em especial da Resolução 196/1996 do Conselho Nacional de Saúde e (ii) a inadequação das diretrizes éticas às pesquisas sociais com metodologias qualitativas, em especial as pesquisas etnográficas.

A pergunta de pesquisa de Luna é clara e busca entender "de que modo essas tecnologias incidem sobre o processo de formação do parentesco" (p. 21). Para respondê-la, a autora faz um longo percurso argumentativo, ora histórico, ora de revisão etnográfica comparada. Por ser uma tarefa ambiciosa em diferentes campos temáticos e conceituais, há capítulos que escapam à pergunta inicial da obra, permitindo digressões pela Teologia, História e Filosofia, certamente uma característica da peça argumentativa que originou a obra - a tese de doutoramento da autora. No entanto, o original da argumentação de Luna é sua aproximação etnográfica, em especial pela apresentação das vozes das mulheres que desafiam a própria capacidade de compreensão da autora e de quem as lê. Foram feitas entrevistas com mulheres e profissionais biomédicos dos serviços e, em vários momentos, a autora contrasta a compreensão destes dois grupos sobre o mesmo fenômeno. Há, todavia, um especial apreço de Luna pelas vozes das mulheres em detrimento das dos profissionais.

Uma experiência comum a todas as etnógrafas do segredo é entender porque as mulheres aceitam contar suas histórias. Luna se faz essa pergunta e aposta na hipótese de que há uma catarse confessional das mulheres no ato de ser ouvida. O convite à pesquisa etnográfica, cuja técnica central é a entrevista aberta, seria um ato de cuidado às mulheres. É preciso lembrar que a infertilidade é um tema tabu não apenas no Brasil, mas em inúmeras sociedades complexas e tradicionais onde o tema da infertilidade já foi investigado 8,9 . No caso das mulheres entrevistadas por Luna, são mulheres com uma longa trajetória de medicalização da infecundidade: regra geral, a chegada aos centros públicos de referência representa a última chance de reversão da condição de infecundidade involuntária.

É preciso fazer uma diferença entre o diagnóstico médico de infertilidade e a condição sociológica de infecundidade involuntária. Muitas mulheres que buscam o auxílio das tecnologias reprodutivas para ter filhos não possuem doenças ou ao menos não há diagnóstico médico para a ausência de filhos. Há casos em que a doença está em seus companheiros, mas é no corpo das mulheres que a medicalização se expressa. Para a ausência involuntária de filhos sem causa médica de infertilidade há outras alternativas disponíveis antes da medicalização intensa do corpo da mulher: desde a adoção de crianças à substituição do companheiro no projeto reprodutivo. No entanto, essas são alternativas desconsideradas pelas mulheres e profissionais biomédicos entrevistados por Luna. É preciso, no entanto, ter clareza de porque essas mulheres rejeitam outros projetos de filiação que não a reprodução biológica.

Luna tem pretensões de descortinar valores compartilhados sobre parentesco e filiação na sociedade brasileira por meio da pesquisa sobre tecnologias reprodutivas. Certamente a pesquisa com usuárias das tecnologias reprodutivas é uma estratégia eficaz, no entanto, há um viés importante na amostra das participantes da pesquisa. Todas são mulheres intensamente engajadas no projeto de reprodução biológica, ou seja, mulheres cujo sentido da maternidade está na expectativa de vinculação biológica com seus futuros filhos. Assim como outras etnógrafas da infertilidade, Luna não conseguiu ter acesso às mulheres que abandonaram o tratamento ou que jamais o buscaram para realizar o desejo por filhos. O mesmo pode ser dito dos profissionais entrevistados: todos estão comprometidos com a reprodução biológica e apostam na medicalização do 
desejo por filhos. Ou seja, é importante relativizar em que momento da trajetória reprodutiva das mulheres o encontro etnográfico ocorreu. Suas opiniões sobre o sentido da maternidade, sobre a importância da filiação biológica, ou mesmo sobre o estatuto do embrião e a rejeição ao aborto representam o momento máximo de aposta na maternidade biológica. Um desdobramento possível da pesquisa etnográfica seria entrevistar novamente essas mulheres em outro momento de suas trajetórias reprodutivas.

Há temas que ainda resistem à pesquisa etnográfica no campo das tecnologias reprodutivas. O primeiro deles, e logo no início da obra reconhecido pela autora como uma ausência de pesquisa, são as histórias das mulheres que desistiram do tratamento ou que nunca o procuraram para resolver a condição de infecundidade involuntária. O segundo é conhecer as experiências masculinas na infertilidade. Ainda não sabemos como os homens se comportam ou vivenciam a experiência de ausência involuntária de filhos. Essa, na verdade, caracteriza uma lacuna internacional nos estudos sobre tecnologias reprodutivas: em geral são mulheres pesquisando mulheres. E, por fim, um tema que salta aos olhos nos hospitais públicos pesquisados por Luna e que desafia a compreensão do acesso às tecnologias reprodutivas como uma expressão do direito constitucional à saúde, é porque somente as mulheres em situação de conjugalidade heterossexual podem ter acesso às tecnologias. Nenhum dos hospitais autorizava que mulheres sozinhas ou lésbicas tivessem acesso às tecnologias reprodutivas, uma restrição que acaba por garantir a presença masculina no projeto reprodutivo das mulheres.

Se, de fato, as tecnologias reprodutivas representam uma revolução no campo reprodutivo, esta revolução não deve ser simplesmente tecnológica ao permitir a geração de embriões fora do corpo da mulher. A verdadeira revolução, a que subverterá os padrões hegemônicos de parentesco e filiação, deverá reconhecer a legitimidade do desejo por filhos para todas as mulheres e homens em idade reprodutiva. $\mathrm{O}$ desejo por filhos não é exclusivo de homens e mulheres heterossexuais em relações afetivas estáveis, como propõe um dos centros públicos pesquisados por Luna. Sendo verdadeiramente uma extensão do direito à saúde, esse deve ser um serviço acessível a todas as pessoas que desejam filhos.

Debora Diniz

Universidade de Brasília, Brasília, Brasil.

anis@anis.org.br

1. Corrêa M. A tecnologia a serviço de um sonho. Um estudo sobre a reprodução assistida no Brasil [Tese de Doutorado]. Rio de Janeiro: Instituto de Medicina Social, Universidade do Estado do Rio de Janeiro; 1997.

2. Barbosa R. Relações de gênero, infertilidade e novas tecnologias reprodutivas. Revista Estudos Feministas 2000; 8:212-28.

3. Rotania A. A celebração do temor: biotecnologias, reprodução, ética e feminismo. Rio de Janeiro: EPapers; 2001.

4. Costa RG. Reprodução e gênero: paternidades, masculinidades e teorias da concepção. Revista Estudos Feministas 2002; 10:339-56.

5. Diniz D, Buglione S. Quem pode ter acesso às tecnologias reprodutivas: diferentes perspectivas do Direito Brasileiro. Brasília: LetrasLivres; 2002.

6. Menegon V. Entre a linguagem dos direitos e a linguagem dos riscos: os consentimentos informados na reprodução humana assistida [Tese de Doutorado]. São Paulo: Pontifícia Universidade Católica de São Paulo; 2003.

7. Grossi M, Porto R, Tamanini M, organizadores. Novas tecnologias reprodutivas conceptivas: questões e desafios. Brasília: LetrasLivres; 2003.

8. Strathern M. Necessidade de pais, necessidade de mães. Revista Estudos Feministas 1995; 3:303-29.

9. Franklin S. Embodied progress: a cultural account of assisted conception. London/New York: Routledge; 1997. 